\title{
Perceptions of Instructional Coaches and Teachers on the Barriers of Multi-Level Instructional Coaching in Higher Performing vs. Lower Performing Elementary Schools in Tennessee
}

\author{
Rose L. Monroe ${ }^{1}$, Stephen Marvin ${ }^{1}$ \\ ${ }^{1}$ College of Education and Behavioral Studies, Freed-Hardeman University, Memphis, Tennessee, USA \\ Correspondence: College of Education and Behavioral Studies, Freed-Hardeman University, Memphis, Tennessee, \\ USA.
}

Received: Nov. 6, 2019

Accepted: June 11, 2020

Online Published: June 17, 2020

doi:10.11114/jets.v8i7.4606

URL: https://doi.org/10.11114/jets.v8i7.4606

\begin{abstract}
Teacher effectiveness is one of the most influential factors on student achievement. Therefore, it is vitally important to appropriately coach teachers toward increased effectiveness. This qualitative research study explored and compared the types of multi-level instructional coaching utilized within higher performing and lower performing elementary schools throughout Tennessee, as identified by both instructional coaches and classroom teachers. Additionally, participants shared their perceptions of the most beneficial aspects of multi-level instructional coaching and the barriers that hinder its productivity. Lastly, participants shared where they could use additional support in relation to instructional coaching. Data were collected through a researcher-created digital questionnaire, consisting of both open-ended and closed-fixed questions. Data were analyzed through qualitative methods, including coding and thematic development. Responses revealed similarities and differences in the responses of instructional coaches and classroom teachers in higher performing and lower performing schools. Among the findings, participants in higher performance schools emphasized that instructional coaching should be targeted to those specific teachers needing help in a particular area; whereas, the participants from lower performing schools overwhelmingly expressed a desire for coaching to assist toward more clearly understanding the best practices associated with instruction. Results from this study may provide stakeholders with data that could encourage modifications to current instructional coaching methods to improve teacher effectiveness.
\end{abstract}

Keyword: instructional coaching, barriers, elementary education, perception

\section{Introduction}

Hartman (2013) suggested that as a result of the increased focus on accountability, the need to increase student scores has become a greater concern, especially within schools that have repeatedly not met Adequate Yearly Progress (AYP) expectations. Similarly, Klein (2015) suggested that those schools that continue to miss achievement targets will likely face state intervention, resulting in either a shutdown of the school, conversion into a charter school, or a state takeover. However, research has identified a connection between instructional coaching and academic gains when teachers effectively implement instructional practices (Polly, Mraz, \& Algozzine, 2013). Instructional coaching, as a professional development strategy, is frequently used to help increase teacher competence (Thomas, Bell, Spelman, \& Briody, 2017). Suarez (2017) similarly noted that instructional coaching is an opportunity for teachers to collaborate with colleagues in order to learn, reflect, and grow. When teachers are given time to reflect upon their existing practices, they are increasingly able to look at their current habits and make deliberate changes that may impact their instruction (Wang, 2017). Wang further noted that having an instructional coach would enable the teachers to be more responsible by giving them more support as they reflect upon their practices. Ultimately, the main goal of instructional coaching is to improve the teachers' instruction and assessment in order to, in turn, improve student achievement (Hartman, 2013).

Because there are different needs in each school district, instructional coaching is not frequently the same from one district to the next (Hartman, 2013). The role of such a coach is also different from state to state and even within some schools (Woulfin \& Rigsby, 2017). Additionally, research has shown that there is a connection between instructional coaching and improved teaching; however, there is little evidence concerning how this coaching helps to improve instruction (Neumerski, 2012). 
An important component for any improvement effort is for teachers to have time to meet and participate in professional development (Gigante \& Firestone, 2008). Wang (2017) explained that schools should not have a one-size fits all approach to professional development because that does not meet the needs of all teachers. Wang further noted that professional development workshops may provide new ideas for teachers, but coaching provides a space for teachers to take what they have learned and apply it in their classroom setting with the help of their coach. Research has also indicated that teachers tend to appreciate instructional coaching more than traditional forms of professional development (Wood et al., 2016). When instructional coaching is intentionally planned and the success factors are addressed, coaching can carry out its promise of making a real difference in schools (Knight, 2006).

Wood et al. (2016) noted that teachers need to be trained in evidence-based practices to ensure that students are taught using methods that have demonstrated their success. Wood et al. further recommended multi-leveled instructional coaching, which consists of high-quality professional development, follow-up supervisory coaching, and side-by-side coaching for teachers who need additional support. Direct measures of teacher performance and data-based decision making are used to determine movement among the levels of support (Wood et al., 2016, p. 165). There is a gap in the knowledge of the research on identifying direct and objective measures of both the teachers' and students' performances during multi-level instructional coaching (Wood et al., 2016). Identifying and using these direct and objective measures may contribute to the success of improving the teachers' instructional skills using multi-level instructional coaching, which could ultimately improve student achievement.

\section{Method}

The purpose of this qualitative study was to compare the perceptions of instructional coaches and teachers regarding multi-level instructional coaching in higher performing and lower performing schools in Tennessee. In the current era of high-stakes testing and emphasis on student learning outcomes, instructional coaches have potential to transform the way teachers reflect on their practice (Polly, Mraz, \& Algozzine, 2013, para. 18). Instructional coaching has been demonstrated to be effective for improving academic instruction, supporting implementation of newly learned strategies, increasing teachers' fidelity of implementation of trained strategies, and increasing student achievement (Wood et al., 2016). Research shows that instructional coaches help with instructional practices and increase student achievement, but the research is limited on how exactly this is achieved (Neumerski, 2012). The goals of the study are to (a) gain an understanding of the teachers' and instructional coaches' perceptions of the effectiveness of instructional coaching and to (b) determine what perceived barriers and/or strengths exist within the teacher and instructional coach relationship. This study will also compare the differences in perceptions that exist between instructional coaches and teachers in higher performing and lower performing schools.

\subsection{Participants}

The target sample for this study included teachers and instructional coaches working in higher performing and lower performing public elementary schools in Tennessee. The teachers were purposefully selected because they were identified as working at a school that had an instructional coach. In this qualitative study, the researcher accessed the Tennessee Value Added Assessment (TVAAS) public website to identify all higher performing and lower performing elementary schools in the state. The schools were identified as higher performing (Level 5) and lower performing (Level 1) based upon the TVAAS overall school-level evaluation composite scores assigned by the Tennessee Department of Education via the public website. There were 457 elementary schools in Tennessee with a Level 5 (higher performing) or Level 1 (lower performing) overall school-level evaluation composite score. From the list of 457 schools, the researcher accessed each school's public website to determine if job titles and email addresses were listed. If this information was publically listed, the researcher ensured that there was an instructional coach listed on the school's website. Out of the 457 elementary schools, twenty-eight (28) higher performing (Level 5) and 19 lower performing (Level 1) schools with instructional coaches were identified from the 3 geographical regions (i.e., Eastern, Central, and Western) in Tennessee. From the schools' public websites, teachers and instructional coaches' e-mails were retrieved. The researcher identified the instructional coach(es) and randomly selected twenty (20) teachers from each school. The teachers and instructional coaches were sent an email which invited them to participate in this research study.

\subsection{Procedures for Data Collection}

The researcher used an electronic questionnaire with open-ended and closed-fixed response questions to collect the data. Collecting is the compilation of important data (Kowalski, Lasley, \& Mahoney, 2008). The participants received an email with a link to the survey. The researcher created 12 different survey links based upon TVAAS level, regions, and job titles. For the eastern region, there were a higher performing survey link for teachers and instructional coaches and a lower performing survey link for teachers and instructional coaches. For the central region, there were a higher performing survey link for teachers and instructional coaches and a lower performing survey link for teachers and 
instructional coaches. For the western region, there were a higher performing survey link for teachers and instructional coaches and a lower performing survey link for teachers and instructional coaches. The identified teachers and instructional coaches received a survey link based upon their TVAAS level and region. As a provision, two follow-up e-mail reminders to complete the survey were sent to all participants. The questionnaire provided feedback on teachers' and instructional coaches' perceptions of effective instructional coaching in relation to teacher effectiveness pertaining to the various types of instructional coaching, benefits and barriers of instructional coaching, and additional support needed with multi-level instructional coaching. Upon completion of the questionnaire, the data were coded and categorized into themes to identify common threads as they emerged through the analysis process. One word or short phrases were used to code the data in order to connect the meaning or categorize the responses from each individual. The process to code the data involved examining one response at a time from the questionnaire. The participants' responses were captured in an Excel spreadsheet and organized by questions. An auditing process took place by utilizing the researcher's dissertation chairperson. Once the first round of coding was complete, the researcher's preliminary list of codes was reviewed to identify overlap in the coding. The research questions were examined again in order to ensure that the analysis of the data aligned with the purpose of the study and supported the instructional coaches' and teachers' thoughts. A visual model was developed to exhibit the general explanation as outlined by Creswell (2015).

\subsection{Procedures for Analysis of Data}

The data for this research were analyzed to allow common threads or connections to emerge among the responses from individuals that related to the purpose of the study. According to Bernhardt (2013), the purpose of the study, as well as the specific research questions, should drive the analysis because it is easy to lose focus by continuing to gather and analyze data and not answer the main questions being researched.

Upon the completion of the data collection process, the researcher examined each question to identify emerging themes. One word or short phrases were used to code the data in order to connect the meaning or categorize the responses from each participant. The process to code the data involved examining one question at a time from the questionnaire. Each question was reviewed one-by-one to connect the meaning of the responses. Charmaz (2001) described coding as the critical link between data collection and its explanation of meaning. As with similar research by Chval et al. (2010), after collecting data in a qualitative study of first year mathematics coaches, the data was analyzed, and coding produced four codes that identified the coaches' roles: (1) coach as supporter of teachers, (2) coach as supporter of students, (3) coach as support of school-at-large, and (4) coach as a learner. Creswell (2015) explained the coding process as a way to make sense out of text data, divide it into text or image segments, label the segments with codes, examine codes for overlap and redundancy, and collapse these codes into broad themes. Once the first round of coding was completed, the researcher's preliminary list of codes was reviewed to identify overlap in the coding. The research questions were examined again in order to ensure that the analysis of the data aligned with the purpose of the study and supported the coaches' and teachers' thoughts. A second round of examining the codes was necessary to make sure that the codes did not need any further modifications.

Data that were not relevant to the research questions and did not align into one of the themes was not utilized in the findings. Comparisons and conclusions were drawn from the data. Creswell (2015) recommends displaying findings in tables and figures and constructing a narrative to explain what you have found in the response to your research questions. To represent the findings, a visual model was developed to exhibit the general explanation as outlined by Creswell (2015).

\section{Results}

Perceived barriers were explored to determine the factors that might prevent an instructional coach from successfully supporting teachers in elementary schools in Tennessee. Data analysis revealed several themes. The researcher desired to identify common themes about perceived barriers of instructional coaching in general, in professional development, side-by-side coaching, supervisory coaching, virtual coaching, any other type of coaching experienced by teachers and instructional coaches in elementary schools in Tennessee.

\section{Barriers to Instructional Coaching}

Instructional coaches in higher performing schools. The resulting themes that emerged for the perceived barriers of instructional coaching as a result of the analysis of the data or instructional coaches in higher performing schools included: (a) limited time and (b) teacher buy-in.

Limited time. Instructional coaches in this study who work in higher performing elementary schools in Tennessee found limited time to be a barrier to the success of instructional coaching. The instructional coaches in this study found that it was difficult to plan during school hours. An important component for any improvement effort is for teachers to 
have time to meet and participate in professional development (Gigante \& Firestone, 2008). With the limited time during school, it is difficult as an instructional coach to get teachers to commit to meeting after school. A lot of teachers have families or scheduled weekly engagements to attend. It is not difficult to find time constraints as a barrier, with the required number of hours each content area must be taught each day.

Teacher buy-in. Instructional coaches in this study who work in higher performing elementary schools in Tennessee perceived teacher buy-in as a barrier to the success of instructional coaching. Instructional coaches in this study found that teachers were resistant to the support being provided. If teachers are resistant, then instructional coaches will not be able to improve instructional practices with the targeted teachers. According to Zeinabadi (2013), social conditions within the school play an important factor to being effective. According to Kutaka et al. (2017), teachers have their own ideas of effective teaching and how students learn. Instructional coaches must build relationships with the teachers to get the teachers to understand that their top priority is the teacher. The support should be non-evaluative.

Teachers in higher performing schools. The resulting themes that emerged for the perceived barriers of instructional coaching as a result of the analysis of the data for teachers in higher performing schools included: (a) utilization of instructional coaches, (b) targeted support, and (c) teacher buy-in.

Utilization of instructional coaches. Teachers in this study who work in higher performing elementary schools in Tennessee perceived how principals utilized instructional coaches to be a barrier to the success of instructional coaching support. Teachers in this study found that principals used the instructional coaches in other administrative roles instead of as a support for new or struggling teachers. Teachers in this study also noted that the instructional coaches were out of the building too often, attending conferences or taking care of other business for the principal. Additionally, teachers in this study were concerned about the instructional coaches taking on an administrative role and treating the teachers like employees. The relationship between the instructional coach and teacher must be one of respect. Teachers tend to appreciate and listen to the instructional coaches when the instructional coach is perceived as a peer. Administrators must be careful of how the instructional coaches are used at their schools. Even though principals are frequently pressured to assign most resources to help prepare for the state assessments (Klein \& Shimoni-Hershkoviz, 2016), there must be guidelines followed on how the instructional coaches' time will be utilized when it comes to providing support at the school.

Targeted support. Teachers in this study who work in higher performing elementary schools in Tennessee perceived targeted support as a barrier to the success of instructional coaching. Some teachers in this study found that principals were not giving teachers a choice, but mandating identified teachers to participate in instructional coaching. Teachers were not happy with receiving instructional support because they suggested that it took too much time away from planning. Additionally, some teachers were concerned about the instructional coaches having too many teachers to support with all of the new teachers at the school. In contrast, some teachers wanted instructional coaches to support all teachers who wanted the support. However, according to Walkowiak (2016), depending on the size of the school and number of teachers at the school, the principal and instructional coach may select certain teachers for the instructional coach to support. Another concern was with all of the targeted teachers; it was too much for one instructional coach to support. There were a range of concerns identified by teachers in this study when it came to targeted support for teachers. However, when instructional coaching is done with fidelity, it takes a lot of the instructional coaches' time to work with teachers. There has to be a limited amount of support if the instructional coaches will be successful. Professional development can be used to reach the masses.

Teacher buy-in. Teachers in this study who work in higher performing elementary schools in Tennessee perceived teacher buy-in to be a barrier to the success of instructional coaching. Teachers in this study found that teachers were not comfortable with others coming into their classrooms to support them. Additionally, teachers in this study felt that receiving instructional coaching support was insulting their ability to teach. Furthermore, teachers who participated in this study noted that instructional coaching sometimes seemed as a waste of time with repetitive trainings. The teachers' failure to believe in the instructional coaches' abilities also was a factor in their refusal to use the instructional coaches as a resource. According to Kutaka et al. (2017), teachers have their own ideas of effective teaching and how students learn. It is not surprising that teachers who have been singled out to receive instructional coaching support feel slighted. For this reason, it is imperative that instructional coaches build the relationship with the teachers. Instructional coaches must listen to the teachers, ask the teachers their ideas and take those ideas and add suggestions based upon those ideas. According to Zeinabadi (2013), social conditions within the school play an important factor to being effective. Schools can influence student achievement by building good relationships among the principal, teachers, and students. When instructional coaches build that relationship with teachers, it breaks down the walls and gets the teachers to trust the instructional coaches' judgment. 
Instructional coaches in lower performing schools. The resulting themes that emerged for the perceived barriers of instructional coaching as a result of the analysis of the data included: (a) trust and (b) utilization of instructional coaches.

Trust. Instructional coaches in this study who work in lower performing elementary schools in Tennessee perceived trust to be a barrier to the success of instructional coaching. Instructional coaches in this study found that there has to be trust among the teachers and instructional coaches. Additionally, a lack of relationship and trust with staff and administration were seen to be barriers to instructional coaching being effective. According to Zeinabadi (2013), it is vital that principals establish a positive relationship with their teachers so that they can increase student achievement. Zeinabadi further noted that if there is no trust or value in the principal's words or actions, then as the leader of the school, it hinders how the followers perceive them. As one participant noted, without trust, there is nothing. I $\mathrm{n}$ order for instructional coaching to work, relationships have to be formed. Teachers must believe in the instructional coaches' abilities, and they must believe that the instructional coach wants them to be successful. Teachers may be leery about the instructional coaches observing their deficiencies and reporting them to the principals. Instructional coaches should hold planning sessions with the teachers, give feedback on observations, and set goals to improve in areas identified. When teachers see the continued positive support of the instructional coaches, teachers should feel comfortable with the instructional coaches being in their classrooms and helping them become more effective.

Utilization of instructional coaches. Instructional coaches in this study who work in lower performing elementary schools in Tennessee perceived that the way administration utilizes instructional coaches as a barrier to the success of instructional coaching. Instructional coaches in this study noted that they did not have the support of administration as they supported the teachers. Administration pulled the instructional coaches for other duties that did not pertain to helping teachers with their instruction. If data show that teachers are not being effective with student achievement, administration should want those teachers to get assistance to improve. As noted by Mette and Riegel (2018), there is a disconnect between school leaders in the ability to understand the teachers' perspective as it relates to the difficulty of teaching and being held accountable through high-stakes testing. If the administration is genuinely concerned about the growth of teachers and not allowing them to fail so that they can be replaced, then the administration will have to allow the instructional coaches to do their jobs.

Teachers in lower performing schools. The resulting themes that emerged for the perceived barriers of instructional coaching as a result of the analysis of the data for teachers in lower performing schools included: (a) utilization of instructional coaches,(b) feedback (negative), (c) non-targeted support, (d) teacher buy-in, and (e) negative relationship.

Utilization of instructional coach. Teachers in this study who work in lower performing schools perceived the way that principals and district leaders utilized instructional coaches as a barrier to success. Teachers in this study found that instructional coaches are assigned too many teachers or schools to support. The teachers in this study also noted that the instructional coaches were in offices instead of coaching. Additionally, teachers who participated in this study suggested that principals had to implement policies sent down from leaders in the district, and this hindered the success of instructional coaching. If instructional coaching is going to be successful, all stakeholders must be on the same page. Even though principals are frequently pressured to assign most resources to help prepare for the state assessments (Klein \& Shimoni-Hershkoviz, 2016), other resources must be allocated to projects that are not part of instructional coaching. Instructional coaches need to coach.

Feedback (negative). Teachers in this study who work in lower performing elementary schools in Tennessee perceived negative feedback as a barrier to the teacher/coach relationship. Although Kurz et al. (2017) noted that part of the coaching cycle included providing feedback, teachers in this study found that some of the instructional coaches' feedback was cruel. Some teachers insinuated that instructional coaches were making up feedback. The teachers in this study wanted the instructional coaches to just focus on the positives instead of making up something that was not beneficial to the teacher. Feedback is a part of the coaching cycle. Teachers are not always following the plan outlined from the collaborative planning that took place with the instructional coach. Instructional coaches must learn to give evaluative feedback in a way that is not condescending.

Non-targeted support. Teachers in this study who work in lower performing elementary schools in Tennessee perceived that not having support targeted for specific teachers as a barrier to the success of instructional coaching. Teachers in this study found that instructional coaching in the form of professional development and classroom support was aimed at the wrong teachers. Teachers in this study suggested that their time is being wasted because they do not need the support. Additionally, teachers felt that instructional coaches were being over worked because they were supporting too many people. Instructional coaching should be productive. The instructional coaches and administrative leaders must outline which teachers need the additional support in the form of instructional coaching. Walkowiak (2016) 
noted that depending on the size of the school and number of teachers at the school, the principal and instructional coach may select certain teachers for the instructional coach to support. The principals should want a school culture that supports the enrichment of teachers.

Teacher buy-in. Teachers in this study who work in lower performing elementary schools in Tennessee perceived not having teacher buy-in as a barrier to the success of instructional coaching. Teachers in this study noted that they did not comply with the instructional coaching because the instructional coaches made demands and did not collaborate with the teachers. Additionally, teachers in this study questioned the competence of the instructional coaches. Instructional coaches must first build positive relationships with the teachers. According to Zeinabadi (2013), social conditions within the school play an important factor to being effective. Next, instructional coaches need to observe teachers to find their level of instruction. Afterwards, the instructional coaches can model best practices for teachers. This will enable the teachers to see the expertise of the instructional coaches in action.

Negative relationship. Teachers in this study who work in lower performing elementary schools in Tennessee perceived negative relationships between the instructional coach and teachers as a barrier to the success of instructional coaching. Teachers that participated in this study found that instructional coaches gossip and share information about teachers that they support. Even when teachers report this abuse to the principals, nothing is done about it. Teachers were feeling uneasy and inadequate at teaching because of the negativity taking place at school. As part of the instructional coaching process, teachers wanted the instructional coaches' supervisors to receive feedback about the conduct of the instructional coaches. Administration should be made aware of the misconduct of instructional coaches. Additionally, instructional coaches have to gain the teachers' trust in order to get them to buy-in to implementing changes that will help their instructional practices. According to Knight (2006, p. 36), instructional coaching is a non-evaluative, learning relationship between a professional developer and a teacher, who share the expressed goal of learning together to improve instruction and student achievement. It all goes back to building positive relationships. To gain the teachers' trust, show them that you care about their success.

Table 1. Summary of the Perceived Barriers on Instructional Coaching

\begin{tabular}{cl}
\hline Participant & Barrier \\
\hline Higher Performing Schools & \\
Instructional Coaches & Limited Time \\
& Teacher Buy-In \\
Teachers & Utilization of Instructional Coaches \\
& Targeted Support \\
& Teacher Buy-In \\
& \\
Lower Performing Schools & Trust \\
Instructional Coaches & Utilization of Instructional Coaches \\
& \\
Teachers & Utilization of Instructional Coaches \\
& Feedback (Evaluative) \\
& Targeted Support \\
& Teacher Buy-In \\
& Negative relationship \\
\hline
\end{tabular}

\section{Conclusions and Discussion}

Instructional coaches in this study who work in higher performing and lower performing elementary schools in Tennessee had different perceptions about the barriers that hindered instructional coaching from being successful. Instructional coaches in this study from higher performing elementary schools perceived limited time and teacher 
buy-in as issues. Teacher buy-in can be detrimental to instructional coaching. From the responses to the research, it is reasonable to wonder if the instructional coaches are focused on building relationships with teachers. School culture may need to be examined. Also, the instructional coaches in higher performing schools who participated in this study did not find the administrators' utilization of instructional coaches as a barrier. The utilization of instructional coaches were found to be a barrier by the instructional coaches in this study who work in lower performing schools, teachers in this study who work in higher performing schools, and teachers in this study who work in lower performing schools. The instructional coaches who participated in this study who work in the higher performing schools were the only ones who did not find this to be a barrier. The teachers in this study from higher performing schools are saying one thing, and the instructional coaches in this study in higher performing schools are saying another. The teachers in this study from higher performing schools perceive that the instructional coaches are being utilized in roles outside of their duties. If that is the case, then maybe the instructional coaches from higher performing schools who participated in this study concur with performing duties that have nothing to do with improving teacher instruction. This could be a factor in why the teachers are not fully buying into support from the instructional coaches.

Instructional coaches in this study who work in lower performing elementary schools perceived trust and how instructional coaches were utilized as barriers to effective instructional coaching. We can assume that at lower performing elementary schools there may be some school culture issues as with the higher performing schools. If there are trust issues among the teachers and instructional coaches or with the instructional coaches and administrators, then instructional coaching will not work. Additionally, when administration utilizes the instructional coaches in a role that does not help the teachers with instruction, it sets the instructional coaches and teachers up for failure.

Teachers in this study who work in higher performing and lower performing elementary schools have concerns about the utilization of the instructional coaches by administration. The administrators appear not to support instructional coaches as an instructional resource for their teachers. Additionally, teacher buy-in at both higher performing and lower performing elementary schools was found to be a barrier by participants of this study. Teachers in this study seem not to fully trust the instructional coaches. Leadership could play a huge role in teachers not fully committing to the instructional coach-teacher relationship. If teachers see the administrators not supporting instructional coaches, then they may feel that they do not have to either.

\section{Implications}

The primary focus of this research study was to get the teachers' and instructional coaches' perceptions of the aspects of instructional coaching that made it effective in improving the teachers' instructional practices. There were many aspects of instructional coaching that was found to be beneficial to improving instructional practices. Additionally, there were aspects of instructional coaching that were perceived to be barriers, and there were additional support that teachers needed in instructional coaching.

Based on the findings from this research, it is reasonable to suggest the following recommendations for practice:

1. Because these findings indicated that principals may be utilizing the in-house instructional coaches in roles that do not support improving teacher instruction, district leaders should consider only using zone or district-level instructional coaches. District leaders may want to look at the schools' budgets and reallocate those funds back to the district office or zones. If the instructional coaches report to someone other than the principal, they may perform job duties related to improving instruction when they visit the different schools.

2. Because the participants at higher performing schools indicated that instructional coaches were just hanging out in the office, the district leaders may want to consider utilizing the instructional coaches assigned to higher performing schools at the lower performing schools. If the case load of new and struggling teachers is minimal at the higher performing schools, the teachers at the lower performing schools may need the expertise. By making this change, all students in the district could grow.

3. Because these findings indicated the misuse of instructional coaching support, principals should monitor how they utilize instructional coaches. The instructional coaches are there to support teachers. When used in roles outside of their job descriptions, such as administrative assistants, it may be a barrier to increasing teacher capacity. If the instructional coaches are utilized correctly, teachers may grow and school accountability scores could improve.

4. Because the findings indicated that classroom observations provide important data, the principals should consider having instructional coaches conduct classroom observations of all teachers. Data from the observations could be used to help identify best practices, professional development needs of the school, and instructional support needs. The instructional coaches and principals should meet often to discuss the state of the school and areas that may need to be addressed. 
5. Because the participants found teacher buy-in as a barrier to instructional coaching, principals should consider ways to build a positive school culture that makes it inviting to grow and learn. Some options that may create this type of culture are collaborative lesson studies, differentiated professional development sessions at least once a month, and spotlighting positive collaborative efforts at the school. This effort by the principal may encourage teachers to buy-in to receiving instructional coaching support because the school environment is one of continuous growing and learning.

6. Because the participants in higher performing schools found retention as being beneficial to instructional coaching, principals in lower performing schools might implement strategies that focus on retaining teachers. The principal should work with the instructional coach to make sure that the teachers are learning best practices and gaining content knowledge. As the instructional coach helps to build teacher capacity, the principal should ensure that those teachers will remain at their school.

7. Because participants found negative relationships as a barrier to instructional coaching, the instructional coaches should consider building positive relationships with teachers. At the initial coaching conversation, make teachers feel valued. Instructional coaches may also want to get the teachers' input on areas that they perceive that they need to improve in. By getting the teachers' ideas, this may have a better effect on the teachers buying into the support of instructional coaches. Instead of an authoritative tone, the coaching-teacher relationship should be of peers.

8. Because the findings indicated that reflective practice is beneficial to instructional coaching in higher performing schools, instructional coaches in lower performing schools might incorporate reflective practice using video technology. The teachers could reflect upon their practices by recording lessons of themselves teaching. The teacher would watch the recording of the lesson, reflect upon the lesson by answering questions provided by the instructional coach, and then collaboratively discuss the video and reflections with the instructional coach. Teachers would be the only ones with access to the video and could delete the video at any time.

\section{References}

Bernhardt, V. (2013). Data analysis for continuous school improvement. New York, NY: Routledge. https://doi.org/10.4324/9781315813356

Charmaz, K. (2001). Grounded Theory. In: Emerson, R.M., Ed., Contemporary field research: Perspectives and formulations, 335-352. Prospect Heights, IL: Waveland Press.

Chval, K., Arbaugh, F., Lannin, J., van Garderen, D., Cummings, L., Estapa, A., \& Huey, M. (2010). The transition from experienced teacher to mathematics coach. The Elementary School Journal, 111(1), 191-216. https://doi.org/10.1086/653475

Creswell, J. (2015). Educational research: planning, conducting, and evaluating quantitative and qualitative research. Upper Saddle River, NJ: Pearson Education, Inc.

Gigante, N., \& Firestone, W. (2008). Administrative support and teacher leadership in schools implementing reform. Journal of Educational Administration: Armidale, 46(3), 302-331. https://doi.org/10.1108/09578230810869266

Hartman, S. (2013). Math coaching in a rural school: Gaining entry: A vital first step. Journal of Education, 193(3), 57-67. https://doi.org/10.1177/002205741319300107

Klein, A. (2015). No child left behind: An overview. Education Week. Retrieved August 30, 2018 from https://www.edweek.org/ew/section/multimedia/no-child-left-behind-overview-definition-summary.html

Klein, J., \& Shimoni-Hershkoviz, L. (2016). The contribution of privatization and competition in the education system to the development of an informal management culture in schools. The International Journal of Educational Management: Bradford, 30(4), 552-570. https://doi.org/10.1108/IJEM-08-2014-0113

Knight, J. (2006). Instructional coaching. School Administrator, 63(4), 36-36.

Kowalski, T., Lasley II, T., \& Mahoney, J. (2008). Data-driven decisions and school leadership: Best practices for school improvement. Boston, MA: Pearson Education, Inc.

Kurz, A., Reddy, L., \& Glover, T. (2017). A multidisciplinary framework of instructional coaching. Theory Into Practice, 56(1), 66-77. https://doi.org/10.1080/00405841.2016.1260404

Kutaka, T. S., Smith, W. M., Albano, A. D., Edwards, C. P., Ren, L., Beattie, H. L., ... Stroup, W. W. (2017). Connecting teacher professional development and student mathematics achievement: A 4-year study of an elementary mathematics specialist program. Journal of Teacher Education, 68(2), 140-154. https://doi.org/10.1177/0022487116687551 
Mette, I., \& Riegel, L. (2018). Supervision, systems thinking, and the impact of American school reform efforts on instructional leadership. Journal of Cases in Educational Leadership, 21(1), 1-18. https://doi.org/10.1177/1555458918759696

Neumerski, C. (2012). Rethinking instructional leadership, a review: What we know about principal, teacher, and coach instructional leadership, and where should we go from here? Educational Administration Quarterly, 49(2), 310-347. https://doi.org/10.1177/0013161X12456700

Polly, D., Mraz, M., \& Algozzine, R. (2013). Implications for developing and researching elementary school mathematics coaches. School Science and Mathematics, 113(6), 297-307. https://doi.org/10.1111/ssm.12029

Thomas, E., Bell, D., Spelman, M., \& Briody, J. (2015). The growth of instructional coaching partner conversations in a PreK-3rd grade teacher professional development experience. Journal of Adult Education, 44(2), 1-6.

Walkowiak, T. (2016). Five essential practices for communication: The work of instructional coaches. The Clearing House, 89(1), 14-17. https://doi.org/10.1080/00098655.2015.1121121

Wang, S. (2017). Teacher centered coaching: An instructional coaching model. Mid-Western Educational Researcher, 29(1), 20-39.

Wood, C., Goodnight, C., Bethune, K., Preston, A., \& Cleaver, S. (2016). Role of professional development and multi-level coaching in promoting evidence-based practice in education. Learning Disabilities: A Contemporary Journal, 14(2),159-170.

Woulfin, S., \& Rigby, J. (2017). Coaching for coherence: How instructional coaches lead change in the evaluation era. Educational Researcher, 46(6), 323-328. https://doi.org/10.3102/0013189X17725525

Zeinabadi, H. R. (2013). Principal-teacher high-quality exchange indicators and student achievement: Testing a model. Journal of Educational Administration, 52(3), 404-420. https://doi.org/10.1108/JEA-05-2012-0056

\section{Copyrights}

Copyright for this article is retained by the author(s), with first publication rights granted to the journal.

This is an open-access article distributed under the terms and conditions of the Creative Commons Attribution license which permits unrestricted use, distribution, and reproduction in any medium, provided the original work is properly cited. 